\title{
Linguistic difficulties in language and reading development constrain skilled adult reading
}

\author{
CONRAD PERRY \\ Macquarie University, Sydney, New South Wales, Australia \\ and \\ JOHANNES C. ZIEGLER \\ Macquarie University, Sydney, New South Wales, Australia \\ and CREPCO-CNRS, Aix-en-Provence, France
}

\begin{abstract}
This study investigated whether the quality and specification of phonological representations in early language development would predict later skilled reading. Two perceptual identification experiments were performed with skilled readers. In Experiment 1, spelling difficulties in Grade 1 were used as a proxy measure for poorly specified representations in early language development. In Experiment 2, difficulties in perceiving and representing liquid and nasalized phonemes in final consonant clusters were used for the same purpose. Both experiments showed that words that were more likely to develop underspecified lexical representations in early language development remained more difficult in skilled reading. This finding suggests that early linguistic difficulties in speech perception and structuring of lexical representations may constrain the long-term organization and dynamics of the skilled adult reading system. The present data thus challenge the assumption that skilled reading can be fully understood without taking into account linguistic constraints acting upon the beginning reader.
\end{abstract}

Much of the literature on adult reading has examined the processes underlying skilled reading without considering developmental constraints. That is, it has been assumed that once the skilled reading system has reached its "final" state, it does not matter much how it actually got there. Such a way of thinking ignores the possibility that different words may acquire different kinds of representations in the course of language development. Instead, it is often assumed that the "final" representations underlying skilled reading are identical across all words in terms of their orthographic and phonological specification. Computational models that code all words according to the same representational scheme are good cases in point (e.g., Coltheart, Curtis, Atkins, \& Haller, 1993; Coltheart \& Rastle, 1994; Grainger \& Jacobs, 1996; McClelland \& Rumelhart, 1981; Ziegler, Rey, \& Jacobs, 1998).

The developmental literature, in contrast, investigates reading from a more continuous perspective (e.g., Duncan, Seymour, \& Hill, 1997; Frith, 1986; Goswami, 1993; Goswami \& Bryant, 1990; Kavanagh \& Mattingly, 1972;

This work was partially supported by a special investigator grant awarded to Max Coltheart and an ARC postdoctoral fellowship awarded to J.C.Z. We are grateful to Arnaud Rey for providing the software of the perceptual identification task. Special thanks to Usha Goswami, who gave invaluable feedback on several occasions. We also wish to thank Judy Bowey, Max Coltheart, and an anonymous reviewer for helpful comments on a previous version of this paper. Individual item means can be obtained from C.P. on request. Correspondence should be addressed to C. Perry, Department of Psychology, Macquarie University, N.S.W., Australia (e-mail: conrad@maccs.bhs.mq.edu.au).
Treiman, 1992). One major idea is that phonological representations are gradually restructured throughout development. Initial word representations are thought to be relatively holistic. However, as vocabulary grows, the need to discriminate between similar sounding words forces lexical representations to become increasingly segmental. As a consequence, smaller segments such as syllables, rimes, and ultimately phonemes become represented (Fowler, 1991; Goswami, 2000; Metsala \& Walley, 1998; Swan \& Goswami, 1997a; Walley, 1993). This segmental restructuring does not occur in an all-or-none systemwide fashion, but on an item-by-item basis (Metsala, 1997a). Some words would experience more pressure to develop well-specified segmental representations than others. Thus, in contrast to the adult perspective, the developmental perspective naturally predicts that different words can acquire different kinds of lexical representations during the course of development.

There is increasing evidence that the quality of these phonological representations plays a causal role in language and reading development. For example, phonemic awareness ability, which is thought to reflect the degree to which segmental restructuring has taken place, is a potent predictor of future reading achievement (e.g., Bradley \& Bryant, 1983; Goswami \& Bryant, 1990; Lundberg, Frost, \& Petersen, 1988). Also, there is increasing consensus that poorly specified, imprecise, or inadequate phonological representations are a major factor underlying reading impairment (e.g., Fowler, 1991; Metsala, 1997b; Snowling, Goulandris, Bowlby, \& Howell, 1986; Swan \& Goswami, 1997a, 1997b). Finally, reading and spelling 
acquisition both affect the phonemic level of representation (Goswami, 2000; Goswami \& Bryant, 1990).

The present article investigated whether phonological representation quality in early language development is a predictor of skilled adult reading. Our goal was to show that words, which are likely to have less well specified phonological representations during early language and spelling development, remain more difficult to process for the skilled adult reader, despite variables known to affect skilled reading being equal. For this purpose, we compared the perceptual identification performance of skilled readers on two groups of words: one group for which the development of fully specified phonological representations should have been easy and another group for which the development of such representations should have been harder.

In Experiment 1, the spelling difficulty of children in Grade 1 was used as an index for the quality of phonological representations during early reading development. In Experiment 2, difficulty in perceiving and representing nasalized or liquid coda consonants was used for the same purpose. In both experiments, the two groups of items were matched on variables that were known to affect skilled reading from the adult perspective. Thus, if early developmental patterns affect the permanent organizational structure of the skilled reading system, we would expect differences between those groups of words, for which the development of phonological representations would have been different. In contrast, if early developmental constraints become superfluous or if the specificity of phonological representations reaches a ceiling, early developmental patterns should have no effect on later skilled reading.

These predictions were tested in a perceptual identification task developed by Rey, Jacobs, Schmidt-Weigand, and Ziegler (1998). In this task, subjects are asked to identify as quickly as possible words on a computer screen that become gradually more visible through an increase in luminance. This task was ideal for our study because it requires subjects to fully identify the words while reducing decision processes associated with the more commonly used lexical decision task.

\section{EXPERIMENT 1}

In the first phase of this experiment, it was necessary to find a measure that would allow us to estimate which kind of items were more likely than others to exhibit poor phonological representation development during early language and spelling development. For this purpose, we examined a rich database on children's spelling collected by Treiman (1993). Because spelling requires children to adequately break down the sound of a whole word into smaller parts, spelling difficulties can be seen as a reliable measure for the quality of children's lexical representations. Moreover, given that learning to read and spell may be a major force in driving segmental restructuring (for a review, see Goswami, 2000), spelling difficulties provide information on the degree to which segmental restructuring has taken place. Thus, Treiman's (1993) database was used as an independent a priori method for selecting words that were difficult for children to spell and hence would be likely to have had poorer phonological representations during reading and spelling development.

Two groups of words were selected that contained either difficult or easy phoneme-grapheme correspondences according to the Treiman database. Difficult correspondences were those that were spelled incorrectly more than $50 \%$ of the time (from Treiman, 1993, Appendix A). These two groups were matched on a number of dimensions known to influence word identification according to the adult perspective, including word frequency, letter and body neighborhood, grapheme complexity, regularity, and consistency. Thus, this manipulation made it possible to address a simple question: Do words that were difficult for children to spell remain slower to process for adults? Under the assumption that spelling performance is a reliable index for the quality of lexical representations in early language development, finding differences between the groups with hard and easy correspondences would suggest that representations that were less well specified for children might remain less well specified for skilled readers.

\section{Method}

Subjects. Twenty-four students enrolled in a first-year psychology course at Macquarie University participated in the study as part of a course requirement. All were native English speakers.

Stimuli. Forty words were used in the present experiment. Twenty words contained phoneme--grapheme correspondences that were difficult to spell according to Treiman's (1993) Grade 1 database; 20 words used correspondences that were easy to spell according to the same database. Difficult correspondences were considered those that had over a $50 \%$ error rate in Treiman (1993). To increase the number of items without excessively repeating the same correspondences, five words with sonorous initial coda consonants were used in the difficult set. Treiman, Zukowski, and Daylene (1995) found that children have difficulty perceiving those phonemes in that type of word.

Both groups were matched pairwise on number of graphemes, phonemic structure, length, body neighborhood ( $B N$, Forster \& Taft, 1994; Ziegler \& Perry, 1998), orthographic neighborhood ( $N$, Coltheart, Davelaar, Jonasson, \& Besner, 1977), CELEX word frequency (Baayen, Piepenbrock, \& van Rijn, 1993), and consistency (Treiman, Mullenix, Bijeljac-Babic, \& Richmond-Welty, 1995). The mean values for the last four variables appear in Table 1. Eight additional words were used as training items to familiarize subjects with the task.

Procedure. The luminance increment procedure was used (Rey et al., 1998). In this procedure, stimuli are presented at a gradually increasing illumination on the screen. That is, words are invisible at first (i.e., they start out black on black) but become gradually more visible as the luminance of the word increases. Subjects are asked to interrupt the incremental procedure when they have identified the word by pressing a key on the computer keyboard. Once a key 
Table 1

Item Characteristics, Mean Reaction Times (RTs), and Percentage of Errors for Words Used in Experiment 1

\begin{tabular}{lccccc}
\hline & \multicolumn{2}{c}{ Easy } & & \multicolumn{2}{c}{ Hard } \\
\cline { 2 - 3 } \cline { 5 - 6 } & RT & $S D$ & & RT & $S D$ \\
\hline Frequency & 220 & 334 & & 220 & 342 \\
$N$ & 6.75 & 4.84 & & 7.05 & 5.16 \\
$B N$ & 10.80 & 4.51 & & 10.15 & 4.17 \\
No. irregular words* & & 1 & & & 2 \\
Friend-enemy ratio & .97 & .14 & & .94 & .15 \\
Mean RT & 1,328 & 40 & & 1,361 & 48 \\
\% Error & 4.38 & 3.97 & & 3.54 & 3.65 \\
\hline
\end{tabular}

Note- $N$, number of letter neighbors; $B N$, number of body neighbors. *Multisyllabic words were not included in the regularity or consistency analysis.

has been pressed, the stimulus is removed from the screen. Subjects then type their response using the computer keyboard. The time from the onset of the stimulus until the subject's response is recorded. Items were presented in a pseudorandom order to each subject. The eight training items were always presented first.

There are some major advantages of the luminance increment procedure: First, in addition to error rate (the only dependent variable typically used in standard perceptual identification tasks like backward masking), the luminance increment procedure makes it possible to obtain identification latencies. Second, because the procedure does not require stimulus quality to be degraded by a mask, the procedure is less susceptible to effects of sophisticated guessing. Third, unlike the lexical decision task, it requires no nonwords to be used. Fourth, since the task does not require a vocalized response (as in reading aloud), it is not susceptible to articulatory onset influences that affect the voice key differently for words with different onsets. Finally, subjects seem to experience lower levels of frustration in the luminance increment procedure than in procedures that rely on stimulus degradation and brief presentation.

\section{Results and Discussion}

Responses to items $3 S D$ above or below the individual grand means were considered errors. This procedure affected $1.15 \%$ of the data. The overall error rate including errors due to outliers was $3.96 \%$. Latencies on error trials were excluded from the latency analysis. All reported effects are significant at or beyond the .05 level unless otherwise noted. Mean response latencies and errors appear in Table 1.

Overall, the mean response latencies went $33 \mathrm{msec}$ in the expected direction. That is, words containing correspondences difficult for Grade 1 children to spell were responded to more slowly than words containing correspondences that were not difficult $(1,361 \mathrm{msec}$ and $1,328 \mathrm{msec}$, respectively). The result was significant by subjects and items $\left[t_{1}(23)=3.01, S E=14.45 ; t_{2}(38)=\right.$ $2.39, S E=14.03]$. In the error analysis, there were no significant differences between the two groups (both $t \mathrm{~s}<$ 1). These results confirmed our prediction that words with segments that were hard to spell for children in Grade 1 were also slower to identify for adults. If spelling difficulty is taken as a measure of poorly specified lexical representations, our data seem to suggest that items that are less well specified early in life might remain less well specified even in skilled reading.

\section{EXPERIMENT 2}

In the previous experiment, spelling difficulty in Grade 1 was used as a measure of the quality of lexical representations early in reading development. In Experiment 2, we used a more direct measure of the quality of phonological representations, namely early difficulties in perceiving and representing particular speech segments. Notably, Read (1975) pointed out that children exhibit difficulty in perceiving nasal sounds in final consonant clusters (codas) if those sounds occur in the first position of a complex (i.e., multiphoneme) coda (e.g., $/ \mathrm{m} /$ in hump). Similarly, Treiman, Zukowski, and Daylene (1995) showed that children have difficulties in representing both nasalized and liquid consonants (e.g., the $/ 1 /$ in wilt) if they are the coda-initial phoneme in a complex coda cluster. When they compared the writings of consonant-consonant-vowel-consonant (CCVC) structures (e.g., crab) with consonant-vowel-consonant-consonant (CVCC) structures (e.g., wilt), they found that children often left out coda-initial nasalized and liquid phonemes in CVCC words. This suggests that the phonological representations of words with nasalized or liquid sounds in the final consonant cluster were more poorly specified than words that did not contain such sound segments.

If the developmental literature is correct in suggesting that children show difficulties in perceiving, segmenting, and representing words with nasalized and liquid codainitial sounds, then we should replicate our previous effects when using difficulty of perceiving coda-initial nasalized and liquid sounds rather than spelling difficulty as an independent measure of the quality of phonological representations during reading development. Thus, our major assumption was that early phonetic effects should provide a reliable measure of how well specified children's phonological representations are. On the basis of the results of our previous experiment, we predicted that words with poor phonological representations in childhood should also be slower to process in adulthood. To test this prediction, three groups of words were selected that differed in terms of whether they contained particular sound segments that were likely to be hard to perceive during early language and reading development. In particular, we compared CVCC words that contained nasalized or liquid coda-initial consonants (e.g., wilt) both with words that had the same CVCC structure but no nasalized or liquid sounds (e.g., lisp) and with a group of CCVC words (e.g., $c r a b)$. The groups were again matched on critical variables shown to influence reading from the adult perspective. Thus any differences between the three groups would suggest that inadequate phonological representations produced by difficulties in phonetic perception in early language development can have long-term effects on skilled reading performance.

\section{Method}

Subjects. Twenty-three first-year Macquarie University psychology students participated in the study as part of a course require- 
ment. None of them had participated in the previous experiment. All were native speakers of English.

Stimuli. Three groups of words were used. Two of the groups had a CVCC structure (e.g., wilt); the other had a CCVC structure (e.g., crab). One of the CVCC groups used words where the codainitial phoneme was either liquid or nasalized (e.g., wilt, hump). The other group used a coda-initial phoneme that was neither liquid nor nasalized (e.g., rift, lisp). This group served as a control group because it had exactly the same consonant/vowel structure as the first group, but it did not contain liquid or nasalized phonemes. The three groups were matched as closely as possible on N, BN, length, CELEX frequency, regularity, and consistency. The mean values for these variables appear in Table 2 .

Twenty words in both the liquid/nasalized CVCC (e.g., wilt) and the CCVC (e.g., crab) group were four letters long and 20 were five letters long. The four-letter group therefore contained exclusively single-letter grapheme-phoneme correspondences. Such a design was used because it makes it possible to control for a potential confound with number of graphemes and type of grapheme units (i.e., single-letter versus multiletter graphemes). If the five-letter words differed from the four-letter words due to orthographic structure or number or type of grapheme, the effect should interact with word length.

As concerns the nonliquid/nonnasalized control CVCC (e.g., lisp) group, 20 words in this group were four letters long and 18 were five letters long. Only 18 five-letter words were used (as opposed to 20 in the two other groups) because it was impossible to find 20 words that met the strict selection criteria. In the group of five-letter words, 7 of the words had a CCVCC (e.g., crisp) structure while 11 had a CVCC (e.g., theft) structure. Also, the control group included a number of irregular words (e.g., raft). Note, however, that because irregularity should slow down responses in the nonliquid/ nonnasalized CVCC control group, this potential confound would work against our hypothesis of finding differences between the liquid/ nasalized and the nonliquid/nonnasalized CVCC words.

Finally, it should be pointed out that Standard Australian English is very similar to Received Pronunciation. Therefore, we had no reason to believe that Australian children would differ from the children tested by Read (1975) or Treiman, Zukowski, and Daylene (1995) in their ability to perceive liquid/nasalized consonant coda phonemes. If anything at all, Australian children should find it harder to perceive liquid /l/ phonemes in the coda cluster because they are very infrequently vocalized in Standard Australian English (Borowsky \& Horvath, 1997).

\section{Results and Discussion}

Responses to items $3 S D$ above or below the individual grand means were considered errors. This procedure af- fected $1.03 \%$ of the data. The overall error rate was $2.06 \%$. Latencies on errors were excluded from the RT analysis. The results appear in Table 2.

A $3 \times 2$ analysis of variance (ANOVA) (word group $X$ word length) was used to examine the overall pattern of results. The three word groups consisted of the CCVC group, the CVCC nasalized/liquid group, and the CVCC nonnasalized/nonliquid control group. In the latency analysis, there was a significant main effect of word group $\left[F_{1}(2,44)=10.27, M S_{\mathrm{e}}=19,920 ; F_{2}(2,112)=7.69\right.$, $\left.M S_{\mathrm{e}}=18,645\right]$. A significant main effect of word length was also found by items $\left[F_{2}(1,112)=4.06, M S_{\mathrm{e}}=\right.$ 9,749], but not subjects $\left[F_{1}(1,22)=2.85, M S_{\mathrm{e}}=8,820\right.$, $p>.1]$. There was no significant interaction between the effects of these two variables (both $F \mathbf{s}<1$ ). In terms of the error data, there were no significant effects or interactions (all $F \mathrm{~s}<1$ ).

To examine the results in greater detail, three $2 \times 2$ (word group $\times$ word length) ANOVAs were performed to investigate whether sonority in the first phoneme of consonant clusters affected the results and whether differences resulted from consonant-vowel structure. The results showed that CCVC (e.g., crab) words were responded to $40 \mathrm{msec}$ faster (by items) than nasalized/ liquid CVCC words (e.g., wilt). This effect was significant by subjects and items $\left[F_{1}(1,22)=15.10, M S_{\mathrm{e}}=\right.$ 33,$\left.761 ; F_{2}(1,76)=14.32, M S_{\mathrm{e}}=31,296\right]$. There was also a main effect of word length that was almost significant by subjects $\left[F_{1}(1,22)=3.71, M S_{\mathrm{e}}=11,284, p=\right.$ $.066]$ and was significant by items $\left[F_{2}(1,76)=5.206\right.$, $\left.M S_{\mathrm{e}}=11,376\right]$. Importantly, there was no significant interaction between word length and word group (both $F \mathrm{~s}<1)$. In the error analysis, there were no significant differences between any of the groups (all $\left.F_{\mathbf{S}}<1\right)$. The comparison between the CCVC (e.g., crab) words and the nonnasalized/nonliquid CVCC (e.g., lisp) control words showed only a 5-msec difference. This difference was not significant either in the latency or in the error analysis (all $F \mathbf{s}<1$ ). Finally, the liquid/nasalized CVCC (e.g., wilt) words were responded to more slowly than the nonnasalized/nonliquid CVCC (e.g., lisp) control words $\left[F_{1}(1,22)=11.29, M S_{\mathrm{e}}=25,408 ; F_{2}(1,74)=8.92\right.$,

Table 2

Item Characteristics, Mean Reaction Times (RTs), and Percentage of Errors for Word Groups Used in Experiment 2

\begin{tabular}{|c|c|c|c|c|c|c|c|c|c|c|c|c|}
\hline & \multicolumn{6}{|c|}{4 Letter } & \multicolumn{6}{|c|}{5 Letter } \\
\hline & \multicolumn{2}{|c|}{$\mathrm{CCVC}$} & \multicolumn{2}{|c|}{ CVCC(LN) } & \multicolumn{2}{|c|}{ CVCC } & \multicolumn{2}{|c|}{$\mathrm{CCVC}$} & \multicolumn{2}{|c|}{$\mathrm{CVCC}(\mathrm{LN})$} & \multicolumn{2}{|c|}{$\mathrm{CVCC}$} \\
\hline & RT & $S D$ & RT & $S D$ & RT & $S D$ & RT & $S D$ & RT & $S D$ & RT & $S D$ \\
\hline Frequency & 58 & 59 & 49 & 60 & 55 & 56 & 63 & 50 & 56 & 68 & 58 & 59 \\
\hline$N$ & 7.5 & 3.00 & 9.05 & 2.61 & 9.75 & 3.81 & 3.25 & 2.22 & 3.50 & 2.21 & 2.73 & 1.81 \\
\hline$B N$ & 16.7 & 4.09 & 13.7 & 5.36 & 9.1 & 3.65 & 6.6 & 3.53 & 6.4 & 4.93 & 6.0 & 2.70 \\
\hline No. irregular words & \multicolumn{2}{|c|}{0} & \multicolumn{2}{|c|}{0} & \multicolumn{2}{|c|}{2} & \multicolumn{2}{|c|}{0} & \multicolumn{2}{|c|}{0} & \multicolumn{2}{|c|}{7} \\
\hline Friend-enemy ratio & .98 & .03 & .99 & .03 & .98 & .10 & .94 & .19 & .98 & .06 & .93 & .07 \\
\hline Mean RT & 1,392 & 40 & 1,426 & 49 & 1,403 & 53 & 1,410 & 46 & 1,455 & 51 & 1,409 & 54 \\
\hline$\%$ Error & 2.61 & 2.19 & 1.74 & 3.27 & 2.17 & 2.99 & 1.09 & 1.93 & 2.39 & 4.11 & 2.42 & 3.41 \\
\hline
\end{tabular}

Note- $N$, number of letter neighbors; $B N$, number of body neighbors; $\mathrm{CCVC}$, consonant-consonant-vowelconsonant; $\mathrm{CVCC}(\mathrm{LN})$, consonant-vowel-consonant-consonant (liquid or nasalized first coda phoneme); CVCC, consonant-vowel-consonant-consonant (not liquid nor nasalized first coda phoneme). 
$\left.M S_{\mathrm{e}}=23,901\right]$, showing that the effects were not due to consonant-vowel structure but to the existence of a liquid or nasalized phoneme in the coda. There were no significant differences in error rates (both $F \mathrm{~s}<1$ ).

Because the CVCC (e.g., lisp) control words were not perfectly matched with the other groups in terms of regularity and phoneme structure (see Method section), we performed a post hoc analysis removing those words that did not conform to a CVCC structure or that had irregular correspondences. Two $2 \times 2$ ANOVAs with word group and word length as factors revealed essentially identical results to those reported above. The CVCC (e.g., wilt) words with a nasal/liquid coda-initial phoneme were significantly slower than the CVCC (e.g., lisp) control words $\left[F_{1}(1,22)=4.85, M S_{\mathrm{e}}=14,635 ; F_{2}(1,65)=4.27, M S_{\mathrm{e}}=\right.$ $11,830]$. The CCVC (e.g., crab) words were not significantly faster than the CVCC (e.g., lisp) control words (both $p s>.10)$. There were no significant differences in error rates (all $F \mathrm{~s}<1$ ).

The results clearly demonstrate that people were slower to respond to CVCC (e.g., wilt) words with a nasalized or liquid first-coda phoneme relative to either CVCC (e.g., lisp) words that did not use such a coda phoneme or CCVC (e.g., crab) words. Together, the results of this experiment join our previous results to suggest that words that are more likely to develop poor phonological representations in early reading, as predicted by difficulties in perceiving liquid and nasalized coda segments, remain more difficult to identify for the skilled reader, despite other variables being equal.

\section{GENERAL DISCUSSION}

In the present study, we challenged the view in the skilled reading literature, according to which skilled reading can be completely understood without taking into account linguistic constraints acting upon the beginning reader. Our claim was that early linguistic constraints in language representation should affect the quality of lexical representations serving as a basis for reading acquisition and that these effects might have long-term consequences for skilled reading. This prediction was tested in two perceptual identification experiments with skilled readers. We compared the performance of different words that were matched on all variables that should matter from the adult reading perspective. Thus, the adult reading perspective predicted no differences between these words. The critical manipulation was that these words differed in the likelihood with which they would have caused early linguistic difficulties during language development, which, in turn, should have affected the construction of fully specified lexical representations. In Experiment 1, we used spelling difficulties in Grade 1 as a measure for poorly specified representations in early reading development. In Experiment 2, we used difficulties in perceiving and representing liquid and nasalized phonemes in final consonant clusters for the same purpose. Our results clearly showed that words which were more likely to develop poor lexical representations in early reading remained more difficult in skilled reading.

Such a finding suggests that reading is continuous in development and that early linguistic difficulties in speech perception and the specification of lexical representations seem to affect the long-term organization and dynamics of the skilled adult reading system. If the development of word representations for individual words is shaped by such early linguistic experiences, it implies that the "final" word representations underlying skilled reading are not identical across all words. Thus computational models that assume that all words are coded according to the same representational scheme remain incomplete. More importantly, there may be aspects about the organization and dynamics of lexical structures that cannot be captured from a static adult perspective of skilled reading.

From the perspective of multiple sources of constraint acting upon reading development, our results show the need for adding developmental constraints onto the list. Thus, there may be statistical and functional constraints on reading development that can be perfectly studied from the adult perspective (e.g., Berndt, D'Autrechy, \& Reggia, 1994; Rey et al., 1998; Treiman, Mullennix, et al., 1995), but there are also linguistic constraints that may require a more developmental perspective. It can be easily seen how multiple constraints can act together to determine the salience of particular units. For example, in the case of body/rime effects, which have been studied from the child and adult perspectives (e.g., Forster \& Taft, 1994; Goswami, 1993; Goswami, Gombert, \& Fraca de Barrera, 1998; Ziegler \& Perry, 1998), there is both linguistic and statistical pressure for the development of body/rime units. The linguistic pressure comes from rimes being very salient units in speech perception in the course of early language development (e.g., Goswami, 1997; Goswami \& Bryant, 1990; Kirtley, Bryant, MacLean, \& Bradley, 1989; Treiman, 1985, 1995). The statistical pressure comes from body/rime units being statistically more consistent than other units in reading (Treiman, Mullenix, et al., 1995).

The present results are also relevant for developmental unit models of reading (see Duncan et al., 1997; Goswami, 1993, 1999; Goswami \& Bryant, 1990; Kavanagh \& Mattingly, 1972; Treiman, 1992). Some models suggest that children initially use small-sized graphemephoneme chunks during reading development, while others suggest that children initially start out with bigger units (for a review, see Duncan et al., 1997). It appears that these models are based on conflicting evidence about the size of the subsyllabic units that children use. The large-unit model claims that word perception starts at a whole-word and syllable level, and is then refined to an onset/rime level, and finally to a phoneme level. In con- 
trast, the small-unit theory claims that early in development small chunks emerge first; only later (if ever) would bigger chunks begin to play a role.

However, in more general chunking models, like the one proposed by Van Orden and colleagues (Van Orden \& Goldinger, 1994; Van Orden, Jansen op de Haar, \& Bosman, 1997; Van Orden, Pennington, \& Stone, 1990), no particular grain size (like the grapheme) is necessarily used in reading. There is a pool of correspondences that can vary in size and from person to person. The actual units that develop are susceptible to the three types of constraints (functional, statistical, and linguistic) mentioned earlier. Such a more general view can easily resolve the apparent conflict between small- and large-unit models. If it is assumed that there is no stage where linguistic pressure on reading is totally independent of functional pressure, then early subsyllabic unit development should show signs of pressure from both sources. In this case, the easiest functional units to learn would be those associated with the simplest correspondences - that is, single letterphoneme units (see Rey et al., 1998). The easiest linguistic units, on the other hand, would be those associated with the sounds that can be differentiated most easily during early language development, such as syllables, rimes, and onsets. Because these latter units are larger, they also contain more complex graphemes and more complex spellingto-sound correspondences.

Therefore, the developing reading system would experience dual pressure. The easiest linguistic units would be harder functionally, due to their more complex mappings. In contrast, the easiest functional units would be more difficult linguistically, due to a need for small-unit (phoneme) awareness to differentiate them. Early in reading, such pressure might cause only the easiest units from both functional and linguistic domains to be present (e.g., onsets that are single phonemes). It might therefore be possible to find evidence for both types of units. This suggests that small- and large-unit theories might not be as theoretically opposing as some have suggested (Duncan et al., 1997) - it is just that the tasks that have been used to differentiate them have often tried to find the easiest units formed from different types of pressure.

In conclusion, the present study showed that there are limits as to how well skilled reading can be understood from a purely adult perspective. We showed that words that were more likely to develop underspecified lexical representations during early language development (as indicated by early spelling data) were more likely to be at a disadvantage in skilled reading, despite other factors influencing word recognition being equal. Therefore, our results suggest that some fundamental aspects about adult reading may be missed if developmental patterns that seem to affect the long-term structure and dynamics of the skilled adult reading system are ignored.

\section{REFERENCES}

BaAyen, R. H., Piepenbrock, R., \& van Rijn, H. (1993). The CELEX lexical database [CD-ROM]. University of Pennsylvania, Philadelphia, Linguistic Data Consortium.
Berndt, R. S., D'Autrechy, C. L., \& Reggia, J. A. (1994). Functional pronunciation units in English words. Journal of Experimental Psychology: Learning, Memory, \& Cognition, 20, 977-993.

BorowsKy, T., \& HORVATH, B. (1997). L-vocalization in Australian English. In F. Hinskens, R. Van Hout, \& W. L. Wetzels (Eds.), Variation, change, and phonological theory (pp. 101-123). Amsterdam: John Benjamins.

Bradley, L., \& Bryant, P. E. (1983). Categorising sounds and learning to read: A causal connection. Nature, 310, 419-421.

Coltheart, M., Curtis, B. Atkins, P., \& Haller, M. (1993). Models of reading aloud: Dual-route and parallel-distributed-processing approaches. Psychological Review, 100, 589-608.

Coltheart, M., Davelaar, E., Jonasson, J., \& Besner, D. (1977). Access to the internal lexicon. In S. Dornic (Ed.), Attention and performance IV (pp. 535-555). Hillsdale, NJ : Erlbaum.

Coltheart, M., \& RastLe, K. (1994). Serial processing in reading aloud: Evidence for dual-route models of reading. Journal of Experimental Psychology: Human Perception \& Performance, 20, 1197-1211.

DunCan, L. G., Seymour, P. H. K., \& Hill, S. (1997). How important are rhyme and analogy in beginning reading? Cognition, 63, 171-208.

FoRSTER, K. I., \& TAFT, M. (1994). Bodies, antibodies, and neighborhooddensity effects in masked form priming. Journal of Experimental Psychology: Learning, Memory, \& Cognition, 20, 844-863.

FowLER, A. (1991). How early phonological development might set the stage for phoneme awareness. In S. Brady \& D. Shankweiler (Eds.), Phonological processes in literacy (pp. 97-117). Hillsdale, NJ: Erlbaum.

Frith, U. (1986). A developmental framework for developmental dyslexia. Annals of Dyslexia, 36, 69-81.

GosWAMI, U. (1993). Towards an interactive analogy model of reading development: Decoding vowel graphemes in beginning reading. Journal of Experimental Child Psychology, 56, 443-475.

GosWAMI, U. (1997). Rime-based coding in early reading development in English: Orthographic analogies and rime neighborhoods. In C. Hulme \& J. R. Malatesha (Eds.), Reading and spelling: Development and disorders (pp. 69-86). Mahwah, NJ: Erlbaum.

GosWAMI, U. (1999). Causal connections in beginning reading: The importance of rhyme. Journal of Reading Research, 22, 217-240.

GoswamI, U. (2000). Phonological representations, reading development and dyslexia: Towards a cross-linguistic theoretical framework. Dyslexia, 6, 133-151.

Goswaml, U., \& BRYANT, P. E. (1990). Phonological skills and learning to read. Hillsdale, NJ: Erlbaum.

Goswami, U., Gombert, J. E., \& Fraca de Barrera, L. (1998). Children's orthographic representations and linguistic transparency: Nonsense word reading in English, French, and Spanish. Applied Psycholinguistics, 19, 19-52.

GRAINGER, J., \& JACOBS, A. M. (1996). Orthographic processing in visual word recognition: A multiple read-out model. Psychological Review, 103, 518-565.

Kavanagh, J. F., \& MatTingly, I. G. (1972). Language by ear and by eye: The relationships between speech and reading. Cambridge, MA: MIT Press.

Kirtley, C., Bryant, P., Maclean, M., \& Bradley, L. (1989). Rhyme, rime, and the onset of reading. Journal of Experimental Child Psychology, 48, 224-245.

Lundberg, I., Frost, J., \& Petersen, O.-P. (1988). Effects of an extensive program for stimulating phonological awareness in preschool children. Reading Research Quarterly, 23, 263-284.

MCClelland, J. L., \& Rumelhart, D. E. (1981). An interactive activation model of context effects in letter perception: Part 1. An account of basic findings. Psychological Review, 88, 375-407.

Metsala, J. L. (1997a). An examination of word frequency and neighborhood density in the development of spoken-word recognition. Memory \& Cognition, 25, 47-56.

MetSala, J. L. (1997b). Spoken word recognition in reading disabled children. Journal of Educational Psychology, 89, 159-169.

Metsala, J. L., \& Walley, A. C. (1998). Spoken vocabulary growth and the segmental restructuring of lexical representations: Precursors to phonemic awareness and early reading ability. In J. L. Metsala \& L. C. Ehri (Eds.), Word recognition in beginning literacy (pp. 89120). Hillsdale, NJ: Erlbaum. 
READ, C. (1975). Children's categorization of speech sounds in English (NCTE Research Report No. 17). Urbana, IL: National Council of Teachers of English.

Rey, A., Jacobs, A. M., Schmidt-Weigand, F., \& Ziegler, J. C. (1998). A phoneme effect in visual word recognition. Cognition, 68 B41-B50.

Snowling, M. J., Goulandris, N., Bowlby, M., \& Howell, P. (1986). Segmentation and speech perception in relation to reading skill: A developmental analysis. Journal of Experimental Child Psychology, 41, 489-507.

Swan, D., \& Goswami, U. (1997a). Phonological awareness deficits in developmental dyslexia and the phonological representation hypothesis. Journal of Experimental Child Psychology, 66, 18-41.

Swan, D., \& Goswami, U. (1997b). Picture naming deficits in developmental dyslexia: The phonological representations hypothesis. Brain \& Language, 56, 334-353.

Treiman, R. (1985). Onsets and rimes as units of spoken syllables: Evidence from children. Journal of Experimental Child Psychology, 39, 161-181.

Treiman, R. (1992). The role of intrasyllabic units in learning to read and spell. In P. B. Gough, L. C. Ehri, \& R. Treiman (Eds.), Reading acquisition (pp. 65-106). Hillsdale, NJ: Erlbaum.

Treiman, R. (1993). Beginning to spell. A study of first-grade children New York: Oxford University Press.

Treiman, R. (1995). Errors in short-term memory for speech: A developmental study. Journal of Experimental Psychology: Learning, Memory, \& Cognition, 21, 1197-1208.

Treiman, R., Mullennix, J., Bijeljac-Babic, R., \& RichmondWeLtY, E. D. (1995). The special role of rimes in the description, use, and acquisition of English orthography. Journal of Experimental Psychology: General, 124, 107-136.

Treiman, R., Zukowski, A., \& Daylene, E. R. (1995). What happened to the " $n$ " of sink? Children's spellings of final consonant clusters. Cognition, 55, 1-38

VAN ORden, G. C., \& Goldinger, S. D. (1994). Interdependence of form and function in cognitive systems explains perception of printed words. Journal of Experimental Psychology: Human Perception \& Performance, 20, 1269-1291.

VAN ORdEn, G. C., JANSEN OP de HAAR, M. A. J., \& Bosman, A. M. T. (1997). Complex dynamic systems also predict dissociations, but they do not reduce to autonomous components. Cognitive Neuropsychology, 14, 131-165.

Van Orden, G. C., Pennington, B. F., \& Stone, G. O. (1990). Word identification in reading and the promise of subsymbolic psycholinguistics. Psychological Review, 97, 488-522.

WALLEY, A. C. (1993). The role of vocabulary development in children's spoken word recognition and segmentation ability. Developmental Review, 13, 286-350.

ZiEgler, J. C., \& PeRrY, C. (1998). No more problems in Coltheart's neighborhood: Resolving neighborhood conflicts in the lexical decision task. Cognition, 68, B53-B62.

ZIEGLER, J. C., REY, A., \& JACOBS, A. M. (1998). Simulating individual word identification thresholds and errors in the fragmentation task. Memory \& Cognition, 26, 490-501.

(Manuscript received April 19, 1999; revision accepted for publication September 13, 1999.) 